\title{
A PAISAGEM E O GEOPROCESSAMENTO NO ENSINO DE GEOGRAFIA: UMA ESTRATÉGIA METODOLÓGICA PARA A DISCIPLINA ECOLOGIA DA PAISAGEM
}

\author{
Dário Rodrigues de Melo Junior ${ }^{(a)}$ Tasso Wesley Galeno Barreto ${ }^{(b)}$ Renata dos Santos ${ }^{(c)}$ \\ Kamili Elizama dos Santos Baia ${ }^{(d)}$ \\ (a) Departamento de Filosofia e Ciências Humanas, Universidade Federal do Amapá, dariojr.ap@ hotmail.com \\ (b) Departamento de Filosofia e Ciências Humanas, Universidade Federal do Amapá, wesley.tasso2011 @ gmail.com \\ (c) Departamento de Filosofia e Ciências Humanas, Universidade Federal do Amapá, kamilibaia@ gmail.com

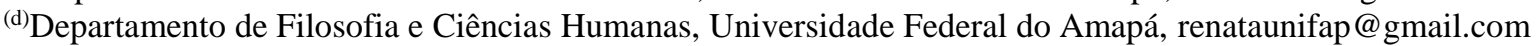

EIXO: GEOGRAFIA FÍSICA: CURRÍCULO, FORMAÇÃO E PRÁTICAS DE ENSINO

\begin{abstract}
Resumo
Este estudo integra uma das atividades proposta durante a disciplina Ecologia da Paisagem ministra no curso de Geografia da Universidade Federal do Amapá. Os discentes tiveram como atividade, analisar o uso e ocupação de terra do campus Marco Zero da UNIFAP. Para isso, foram utilizas técnicas de SIG e arquivos em shapefile. O limite do campus foi recortado das ortoimagens imagens, cedida pela SEMA. As imagens apresentam resolução de 2,5 metros, permitindo identificar as características físicas do compus. Com os dados pode-se elaborar o mapeamento do uso e ocupação da terra da área estudada. Posteriormente analises foram realizadas, indicando como estão dispostos os prédios, arruamentos, machas de vegetação, dentre outros componentes, possibilitando ter uma ideia de como se apresenta a paisagem vertical existente na UNIFAP. O resultado foi exposto em um mosaico de mapas com os aspectos físico da paisagem e um mapa como o uso da terra no campus.
\end{abstract}

Palavras-Chave: Geografia; Ecologia da paisagem; uso e ocupação da terra.

\section{Introdução}

Entender os aspectos físicos da natureza e compreender o comportamento das sociedades com o meio natural e dentro de si mesma é o problema/objeto da ciência Geográfica. É, portanto, de interesse da geografia apreender como cada sociedade humana estrutura e organiza o espaço físico-territorial em face das imposições do meio natural (ROSS, 1995). Para tanto a geografia se utiliza de diferentes categorias de análises, e uma que está em grande ascensão é a paisagem. Trata-se de um dos conceitos chaves da geografia, capaz de promover a unificação e identidade para afirmação da ciência geográfica (SIQUEIRA et al, 2013).

De acordo com Bertrand (1968), a paisagem é uma determinada porção do espaço que resulta da combinação dinâmica dos elementos físicos, biológicos e antrópicos, os quais interagindo dialeticamente uns sobre os outros formam um conjunto único e indissociável em perpétua evolução. Existe certa complexidade para entender a paisagem como ela é, pois é preciso dominar o entendimento das dinâmicas dos elementos da natureza, incluindo as ações antrópicas, para ter uma 
compreensão do produto paisagem. Conforme Salgueiro (2001, p.39), o aparecimento da paisagem foi acompanhado de uma revolução científica e técnica que "libertou a natureza do concurso divino tornando-a objeto de conhecimento e abrindo caminho à sua manipulação e transformação com diversos fins".

Metzger (2001) ressalta, que anteriormente, uma definição integradora de paisagem era vista como "um mosaico heterogêneo formado por unidades interativas, sendo esta heterogeneidade existente para pelo menos um fator, segundo um observador e numa determinada escala de observação".

Dentro a análise da paisagem se destaca a disciplina ecologia da paisagem tendo alguns estudos como os de Siqueira et al (2013) e Metzger (2001) que discorrem sobre as evoluções conceituais e abordagens teóricas dessa jovem disciplina. Esses autores dão mérito aos estudos de Carl Troll, na década de 30, que:

Ao analisar as questões relacionadas ao uso da terra e interpretar as paisagens produzidas por essa relação, resultaram nas concepções da emergente disciplina científica, unificando os conceitos e campos de trabalho da geografia em relação à paisagem e da ecologia em relação ao ambiente natural, conclamando geógrafos e ecologistas a trabalharem em estreita colaboração, denominando a mesma de Geoecologia ou Ecologia da Paisagem (SIQUEIRA et al, 2013, p 558).

Como pressuposto por Siqueira et al, (2013), uma das metodologias de análise da paisagem é através da compreensão do uso e ocupação da terra. Para termos esse entendimento surge o mapeamento como método. Pancher e Rossetti (2012) ressaltam que o "mapa temático de uso e ocupação do solo consiste em instrumento essencial para o conhecimento das características físico-naturais e antrópicas, que permite subsidiar as ações”, muito importante para o planejamento e gestão dos recursos naturais.

No curso de graduação de Geografia o geoprocessamento tem maior presença como disciplina, e assim mesmo, em alguns cursos é eletiva, ou optativa, reduzindo significativamente o número de discentes que se familiarizam com esta ferramenta tecnologia, que pode ser utilizada em vários viés sociais e ambientais. Para o ensino da Geografia, e especialmente, para a conjectura de uma metodologia que considere a utilização de produtos do Sensoriamento Remoto e do geoprocessamento como ferramentas principais, resgatar o estudo do espaço geográfico assume grande importância, na medida em que é a partir dele que se dará início a um processo desencadeador de questões a serem respondidas, não só com referência à geografia física, mas também questões relativas à geografia humana (CARVALHO et al, 2004).

A utilização do geoprocessamento como instrumento pedagógico pode agregar novos olhares ao ensino de geografia física. Mediante que a confecção de mapas, desenvolve no aluno a capacidade de observar, analisar e interpretar a realidade física da Terra em várias dimensões e escalas, produzindo conhecimento. De modo simples e rápido, a utilização de geoprocessamento como ferramenta para a criação cartográfica do espaço geográfico, permiti ao educando, fazer uma análise da paisagem 
XVII Simpósio Brasileiro

de Geografia Fisica Aplicada

I Congresso Nacional

de Geografia Física

\section{OS DESAFIOS DA GEOGRAFIA FÍSICA NA FRONTEIRA DO CONHECIMENTO \\ Instituto de Geociências - Unicamp \\ Campinas - SP \\ 28 de Junho à 02 de Julho de 2017}

verticalmente. A exemplo, este podendo interpretar o relevo, descrever suas formas, entender o porquê dessas formas, bem como a transformação no decorrer do tempo geológico, entender o uso e ocupação dessa paisagem e as dinâmicas sociais e relacionar tudo isso com a sua realidade.

O objetivo do presente trabalho consiste em realizar mapeamento do uso e ocupação de terra do campus Marco Zero da Universidade Federal do Amapá, com o intuito de compreender como se constitui as áreas antropizadas e as áreas ainda com cobertura vegetal do campus. Com a finalidade de confeccionar mapas da área, permitindo um conhecimento ecológico da paisagem em questão e subsidiar um planejamento para a área. Contribuindo também como fixação dos conteúdos propostos na disciplina Ecologia da Paisagem, bem como ampliando de conhecimento da Geografia física.

\section{Metodologia de Trabalho}

\section{1. Área de estudo}

A Universidade Federal do Amapá - UNIFAP é uma Universidade Pública, mantida pela União, criada pela Lei n. 7.530, de 29 de agosto de 1986, e instalada pelo decreto n. 98.977, de 02 de março de 1990, vinculada ao Ministério da Educação, tendo sede no campus Marco Zero que se insere no município de Macapá, do Estado do Amapá, mais precisamente no bairro Universidade, na cidade de Macapá (Figura 1). O campus Marco Zero tem uma área de $877.367 \mathrm{~m}^{2}$.

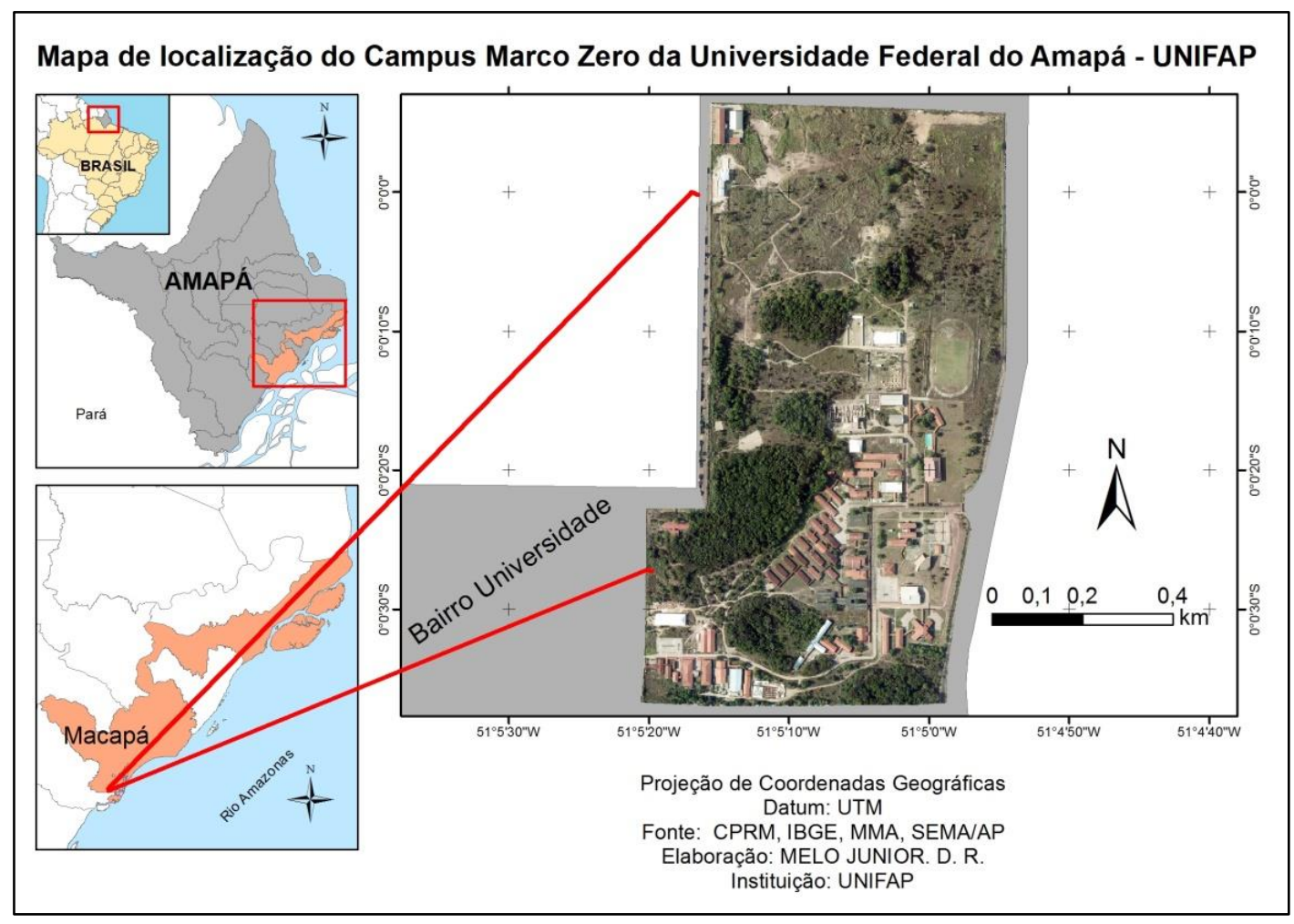

Figura 1 - Mapa de localização do Campus Marco Zero 
OS DESAFIOS DA GEOGRAFIA FÍSICA NA FRONTEIRA DO CONHECIMENTO

Instituto de Geociências - Unicamp

Campinas - SP

28 de Junho à 02 de Julho de 2017

Para alcançar o objeto proposto foram empregadas técnicas de sensoriamento remoto e geoprocessamento. Primeiramente, utilizou-se as ortoimagens de radar de abertura sintética (SAR) com resolução de $2,5 \mathrm{~m}$, que é parte disponível do projeto da base cartográfica digital continua do Estado do Amapá, elaborado pela Secretária de estado do Meio Ambiente (SEMA) e Exército Brasileiro (EB), e os shapefile do bairro Universidade para extrair a área de estudo, criando um recorte da ortoimagem de radar somente da área. Para o processamento digital da imagem, criação e edição dos shapefile foi utilizado o software ArcGIS® versão 10.3.

A partir do shapefile se aplicou métodos de geoprocessamento para extrair as informações de geologia, geomorfologia, solo (pedologia) e vegetação da área, através dos dados do Geobank do Serviço Geológico do Brasil (SPRM). Assim criamos o mapa dos aspectos físicos.

Com a ortoimagem foi realizado classificação resultando no mapa do uso e ocupação. Essa classificação foi feita de forma manual, uma análise visual dos elementos, editando o shapefile da área na tabela de atributos, por se tratar uma área relativamente pequena. Obtendo, assim, as classes objetivadas.

As classes criadas foram: administração, anfiteatro, biblioteca, centro de vivencia, centros de pesquisas, salas de aulas, restaurante, rádio universitária, setor de transporte, unidade básica de saúde, áreas desportivas, escolas, estacionamento, estradas pavimentadas, caminhos não pavimentados, floresta arbórea antropizadas e cerrado arbórea/arbustiva antropizado.

Posteriormente realizou-se a tabulação da estatística de área com a ajuda do programa Microsoft Excel 2010, obtendo o percentual de áreas e construíram-se os gráficos e tabelas.

\section{Resultados}

\subsection{Aspectos físicos}

Os resultados obtidos a partir da aplicação dos procedimentos descritos estão dispostos na sequência na (figura 2). Em que são destacados os aspectos físico da paisagem a saber: geologia, geomorfologia, solo e vegetação. Devido a escala cartográfica ser grande, os aspectos são apresentados de forma continua, homogênea, fazendo com que a área estudada tenha a mesma relevância ambiental.

A área dispõe de uma geologia que é dominante na região, rotulada como unidade Barreiras tendo uma hierarquia de grupo, com a sigla ENb na cartografia geológica. Tendo sua formação na Era Cenozóico, no Período Paleogeno inserida na Época do Paleoceno, isso corresponde cerca de entre 65 a 23.5 milhões de anos. 


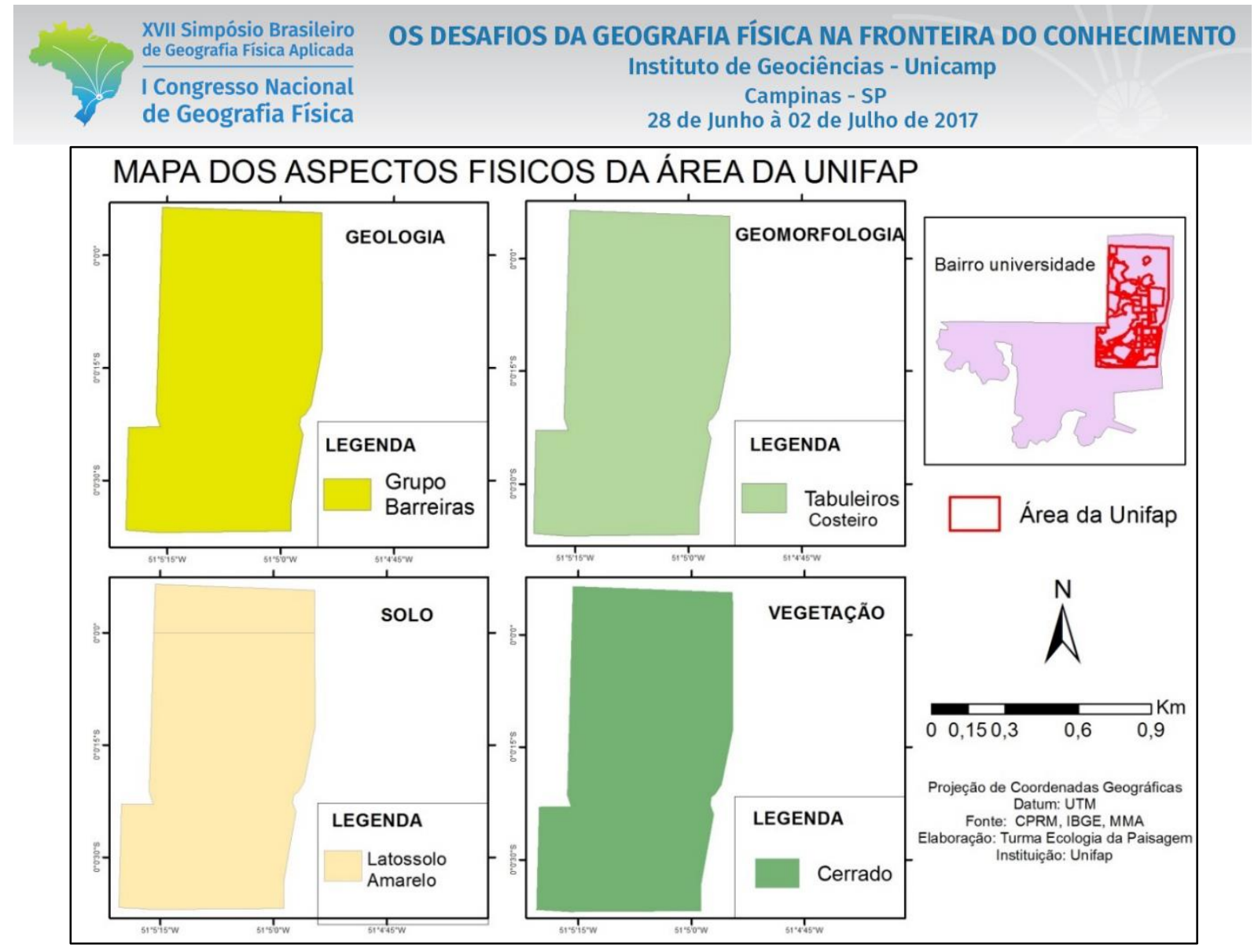

Figura 2 - Mapa dos aspectos físicos da paisagem do Campus Marco Zero

A geomorfologia predominante é representada pelos tabuleiros costeiros, relacionada, segundo estudos junto ao projeto RADAM (apud SANTOS et al, 2004), na categoria de planaltos rebaixados do Amapá. SANTOS et al (2004), descreve que este tipo de relevo predominam "as formas dissecadas em interflúvios tabulares e outras vezes colinosas, com vertentes geralmente apresentando formas de ravinamento. No geral, esses vales são encaixados, tornando-se abertos no limite com a planície costeira".

O Latossolo Amarelo é o tipo de solo na área compreende solos constituídos por material mineral, com horizonte B latossólico imediatamente abaixo de qualquer um dos tipos de horizonte diagnóstico superficial.

O cerrado é o tipo de vegetação predominante, que já nos mostra um pouco do clima, pois o cerrado faz parte dos climas quentes e úmidos, com chuvas torrenciais bem demarcadas pelo período seco e caracterizada sobretudo por árvores tortuosas, de folhas raramente deciduais, como também por formas biológicas adaptadas aos solos deficientes, profundos e aluminizados (RADAMBRASIL, 1974 apund IEPA, 2004).

\subsection{Uso e Ocupação}

Na figura 3 pode observar como se apresenta o uso e ocupação da área do campus da Unifap. 


\section{OS DESAFIOS DA GEOGRAFIA FÍSICA NA FRONTEIRA DO CONHECIMENTO \\ Instituto de Geociências - Unicamp \\ Campinas - SP \\ 28 de Junho à 02 de Julho de 2017}

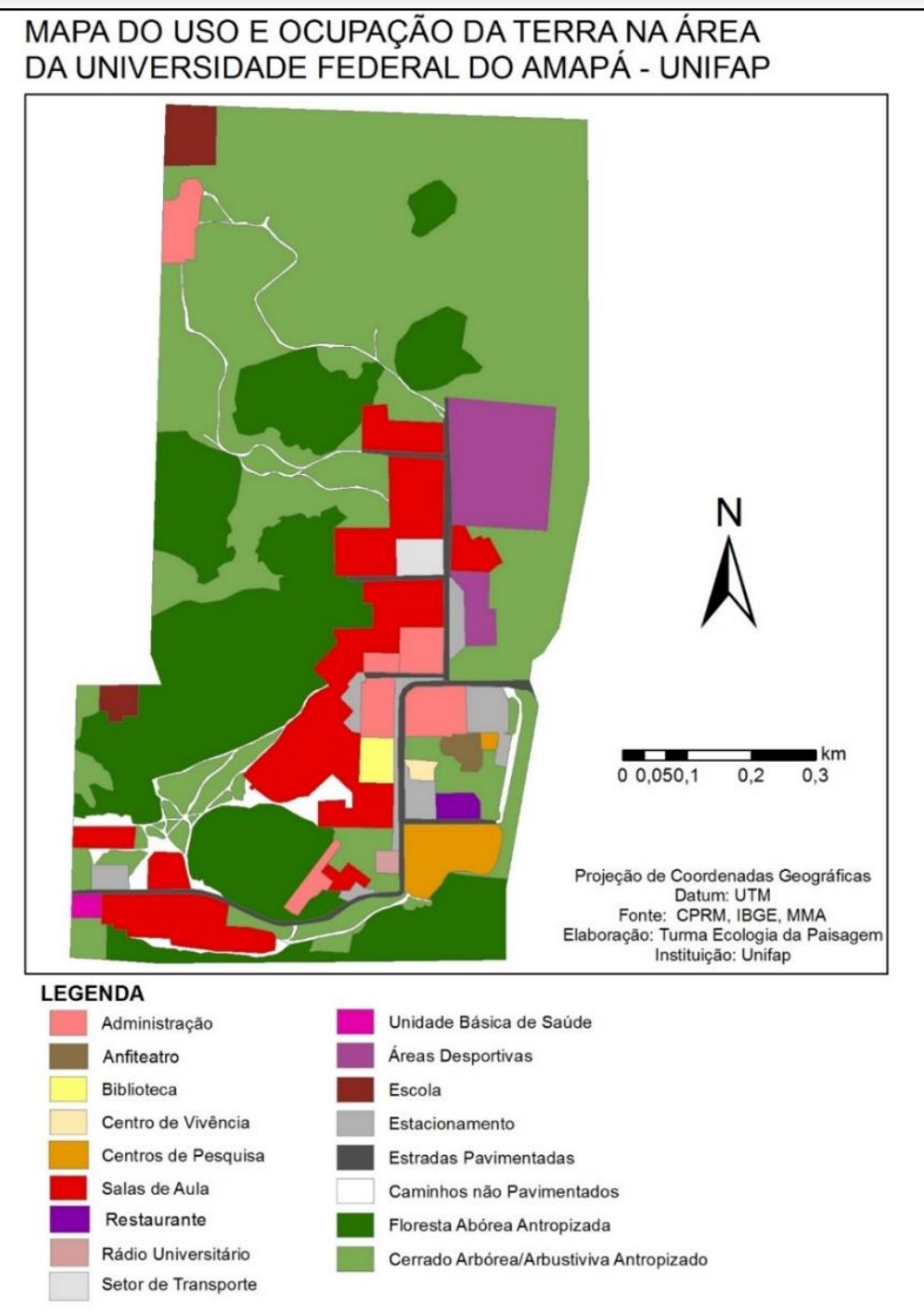

Figura 3 - Mapa de uso e ocupação

Diante da Figura 3, que apresenta a espacialização do uso da terra do campus Marco Zero, mapa temse a estatística de área, que se apresenta na tabela 1.

Tabela 1: Divisão do uso da terra no Campus Marco Zero da Unifap

\begin{tabular}{|c|c|c|}
\hline Classes & Área $\left(\mathrm{m}^{2}\right)$ & Percentual (\%) \\
\hline Administração & 27.958 & $3 \%$ \\
\hline Anfiteatro & 2.943 & $0.02 \%$ \\
\hline Áreas desportivas & 36.073 & $4 \%$ \\
\hline Biblioteca & 3.726 & $0.03 \%$ \\
\hline Centro de vivência & 1.334 & $0.01 \%$ \\
\hline Centros de pesquisas & 13.865 & $2 \%$ \\
\hline Escolas & 10.414 & $1 \%$ \\
\hline Estacionamento & 18.754 & $2 \%$ \\
\hline
\end{tabular}




\begin{tabular}{l|c|c}
\hline $\begin{array}{l}\text { XVII Simpósio Brasileiro } \\
\text { de Geografia Fisica Aplicada }\end{array}$ & $\begin{array}{c}\text { ICongresso Nacional } \\
\text { de Geografia Fisica }\end{array}$ & $\begin{array}{c}\text { OS DESAFIOS DA GEOGRAFIA FíSICA NA FRONTEIRA DO CONHECIMENTO } \\
\text { Instituto de Geociências - Unicamp } \\
\text { Campinas - SP } \\
28 \text { de Junho à 02 de Julho de 2017 }\end{array}$ \\
\hline Salas de aulas & 95.477 & $11 \%$ \\
\hline Restaurante & 2.755 & $0.02 \%$ \\
\hline Rádio universitária & 1.266 & $0.01 \%$ \\
\hline Setor de transporte & 4.120 & $0.04 \%$ \\
\hline Unidade básica de saúde & 1.718 & $0.01 \%$ \\
\hline Estradas pavimentadas & 16.548 & $2 \%$ \\
\hline Caminhos não pavimentados & 24.310 & $3 \%$ \\
\hline Floresta arbórea antropizada & 222.724 & $25 \%$ \\
\hline Cerrado arbórea/arbustiva antropizado & 393.382 & $45 \%$ \\
\hline TOTAL & 877367 & $100 \%$ \\
\hline
\end{tabular}

As regiões sul e sudeste da área, são as que mais estão ocupadas pelos prédios e outros tipos de construção e a região oeste com a presença das mosaicos de florestas e mais ao norte a fisionomia de cerrado predomina.

Separou-se o uso e ocupação em três grandes classes; Áreas construídas, Cerrado, Floresta. A figura 4, mostra o percentual disposta nessa classificação.

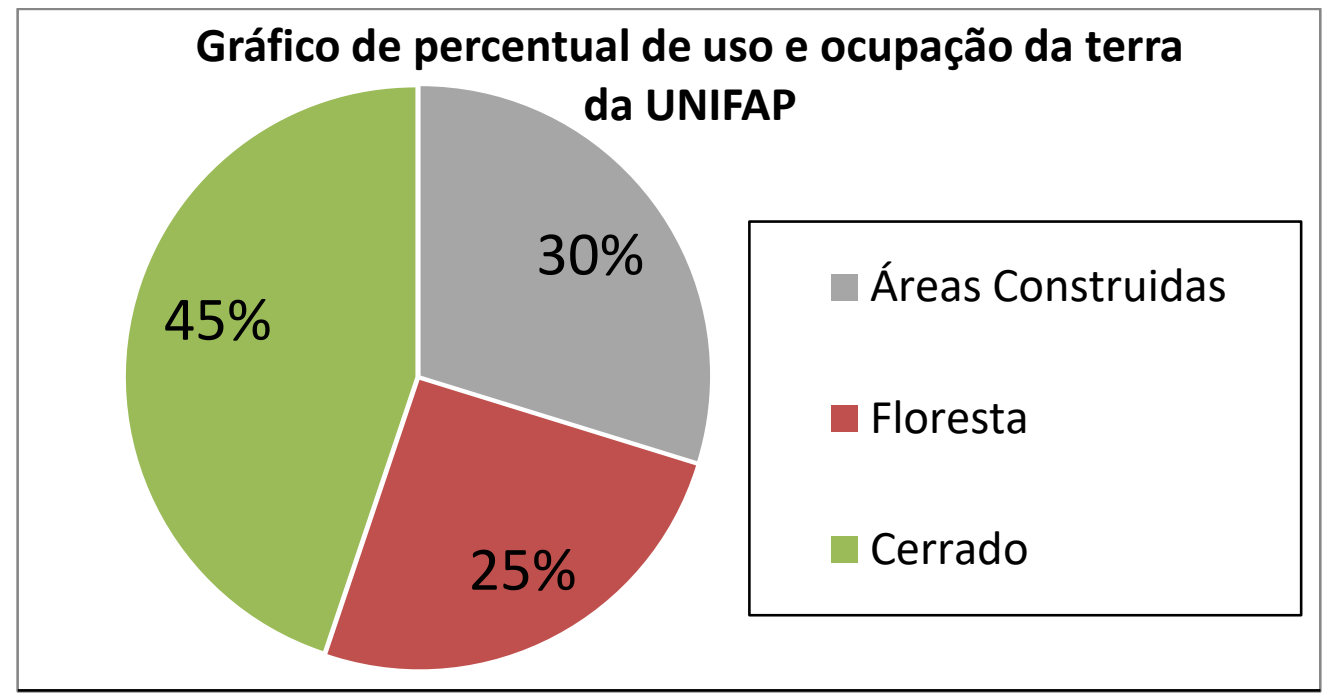

Figura 4 - Gráfico com o percentual de uso e ocupação de terras da UNIFAP.

O campus apresenta $70 \%$ de área com vegetação, que possibilita o uso, para práticas de campo por muitos cursos da universidade como Biologia, Ciências ambientais, geografia e outros. A área floresta 25\% apresenta uma Floresta denominada "mata do Sussurro" muito utilizada para trilhas nas disciplinas biogeografia, pedologia e ecologia da paisagem, que termina na área com fisionomia de cerrado. Possibilitando aos discentes fazer análise da paisagem, firmando os conceitos vistos na sala de aula. 


\section{Consideração final}

A paisagem é um objeto de estudo da ciência geográfica, que caracteriza e analisa suas mudanças ao longo do tempo e espaço. Disciplinas como Ecologia da Paisagem tem a paisagem como objeto principal de estudo, em uma abordagem mais conservacionista e métricas, bem como as variações de analisa-la. Estas podendo serem feitas de forma horizontal e vertical englobando outras ferramentas com o SIG, que possibilita o mapeamento da ocupação e uso da terra, simplificando e ampliando os estudos da paisagem para uma gama de análise e a integração desta na disciplina Ecologia da Paisagem como para tantas outras disciplinas como forma de atividade, aprimorando o conhecimento para o ensino.

\section{RERERÊNCIAS}

BERTRAND, G. Paysage et géigraphie physique: esquisemethodologique. Toulosse: E.G.P.S.O., 1968.

CARVALHO, Vânia Maria S. G; CRUZ, Carla Bernadete M; ROCHA; Elizabeth Maria F.

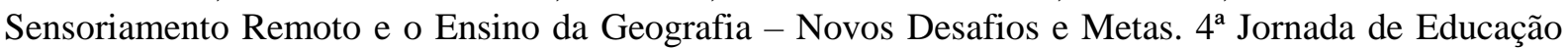
em Sensoriamento Remoto no Âmbito do Mercosul — São Leopoldo, RS, agosto de 2004.

Exército Brasileiro. Centro de informações geográficas do exército - CIGEX. Disponível em <www.ciges.br.mil.br/index.php/ultimas-noticias/82-exercito-assina-convenio-para-mapeamento-do-estado-doamapa> acessado em 30 de ago. 2016.

Instituto de Pesquisa Científicas e Tecnológicas do Estado do Amapá - IEPA. Projeto Zoneamento EcológicoEconômico do Setor Costeiro Estuarino do Estado do Amapá - ZEEC-AP. Programa Estadual de Gerenciamento Costeiro - GERCO/AP. Macapá/AP. 2004.

METZGER, J. P. O que é Ecologia de Paisagens.IN: revista Biota neotropica, v.1, n.1, p. 1-9, 2001.

PANCHER, Andréia M; Rossetti, Lucimari A. F. G.MAPA DE USO E OCUPAÇÃO DO SOLO URBANO: Análise comparativa entre os métodos de classificação manual e digital. 2012.

ROSS, Jurandyr L. Sanches (Org.). Geografia do Brasil. Editora da Universidade de São Paulo. São Paulo. 1995.

Serviço Geológico do Brasil - SPRM. Geobank. Disponível em <http://www.geobank.cprm.gov.br> acessado em 06 de Jul. de 2016.

SALGUEIRO, Teresa Barata. Paisagem e Geografia. In: Finisterra, XXXVI, 72, 2001, pp. 37-53. Disponível em: http://www.ceg.ul.pt/finisterra/numeros/2001-72/72_04.pdf. Acessado em: 20/08/2016.

SANTOS, Valdenira F. dos; ANDRADE, Ana C. da Silva; SILVEIRA, Odete F. M. da; MARTINS, Marcos H. de Abreu; CARVALHO, Fábio P. de. DINÂMICA GEOMORFOLÓGICA. IN: Instituto de Pesquisa Científicas e Tecnológicas do Estado do Amapá - IEPA. Projeto Zoneamento EcológicoEconômico do Setor Costeiro Estuarino do Estado do Amapá - ZEEC-AP. Programa Estadual de Gerenciamento Costeiro - GERCO/AP. Macapá/AP, 2004.

SIQUEIRA, Mariana Nascimento; CASTRO, Selma Simões; FARIA, Karla Maria Silva. Geografia e Ecologia da Paisagem: pontos para discussão. IN: Revista Soc. \& Nat., Uberlândia, 25 (3): 557-566, set/dez/2013. 